Special issue of the 2nd International Conference on Computational and Experimental Science and Engineering (ICCESEN 2015)

\title{
Supervising Water Quality of Water Resources via Telemetric System
}

\author{
İ.S. ÜNCÜ ${ }^{a, *}$ AND M. AKDURUL ${ }^{b}$ \\ ${ }^{a}$ Süleyman Demirel University, Technology Faculty, Electrical and Electronic Engineering Department, \\ Isparta, Turkey \\ ${ }^{b}$ Süleyman Demirel University, Graduate School of Applied and Natural Sciences, \\ Electronic and Computer Education Department, Isparta, Turkey
}

\begin{abstract}
Urban water resources are some of the main places where microorganisms can reproduce and where people can get easily infected. For these reasons, pools must be sterilized continuously. This can only be done if the water quality of the pool is in accordance with the standards of the Ministry of Forestry and Water Affairs. Monitoring water quality in real-time gives an instant response opportunity. With the software prepared using the. Net architecture, real-time temperature, $\mathrm{pH}$, and chlorine content values of a pool were transferred to a database. Swimming pool water quality was then evaluated and compared with the Ministry of Forestry and Water Affairs standards via the expert system technique, which is one of the artificial intelligence technologies. In this study, results of instant evaluation of the water quality made for water resources via telemetric systems, are reported. Additionally, a remotely-controlled dosing operation was performed.
\end{abstract}

DOI: 10.12693/APhysPolA.130.293

PACS/topics: 06.20.Dk, 07.07.Df, 07.88.+y

\section{Introduction}

Besides being a professional sport, swimming is also one of the best sports that can be practiced for a healthy life. Due to practicing this funny sport, the usage of swimming pools is increasing. With the increasing use of the pools, pool water-borne micro-organisms and bacteria become a risk to human health. Since the developed system will be used in Turkey, the standards of this country are considered. Turkish Republic Ministry of Health has made arrangements about indoor and outdoor swimming pools, regarding eligible water hygienic conditions, standards of determination of swimming pool water quality, principles and procedures related to supervision and monitoring, in order to avoid diseases transmitted in the pools [1]. To control the compliance with these principles and procedures, the instant quality assessment of the water was done with a telemetric system. Evaluation results and remotely controlled dosing process are reported.

\section{Methods and materials}

\subsection{Water quality criteria and required standards}

Water quality criteria are the criteria that determine the effects of the foreign and unwanted substances in water on all forms of life in that environment in terms of usage function and what kind of effects will occur on each level of the concentration of undesirable substances.

TABLE I

Classification of quality criteria of inland water resources.

\begin{tabular}{l|c|c|c|c}
\hline \hline \multicolumn{1}{c|}{ Water } & \multicolumn{4}{|c}{ Degrees of water quality } \\
$\begin{array}{c}\text { quality } \\
\text { parameters }\end{array}$ & $\begin{array}{c}\text { II } \\
\text { wigh quality } \\
\text { water }\end{array}$ & $\begin{array}{c}\text { Less contaminated } \\
\text { water }\end{array}$ & $\begin{array}{c}\text { III } \\
\text { Contaminated } \\
\text { water }\end{array}$ & $\begin{array}{c}\text { IV } \\
\text { More contaminated } \\
\text { water }\end{array}$ \\
\hline Temperature, $\left[{ }^{\circ} \mathrm{C}\right]$ & 25 & 25 & 30 & $>30$ \\
$\mathrm{pH}$ & $6.5-8.5$ & $6.5-8.5$ & $6.0-9.0$ & out of $6.0-9.0$ \\
Free chlorine, $\left[\mu \mathrm{g} \mathrm{Cl}_{2} / \mathrm{L}\right]$ & 10 & 10 & 50 & 50
\end{tabular}

*corresponding author; e-mail: serkanuncu@sdu.edu.tr

Water quality standards are determined by laws. These standards may vary by country. In our country "Water Pollution Control Regulation" was published in 2004 by the Ministry of Environment and Forestry. This 
regulation has been prepared in accordance with the law no. 2872 Environmental Law and Law amending additional provisions in the current law and in accordance with the law no. 4856 with the Ministry of Environment and Forestry based on the law on the Organization and Duties. The criteria of classifications of the inland resources in the Water Pollution Control Regulation, that went into effect and was published on 31.12.2004 [2], are given in Table I. In the water quality researches, rather than measuring a large number of parameters, the identification of a smaller number of critical parameters, which were carefully chosen in advance, is performed. These are $\mathrm{pH}$, temperature and chlorine content parameters. Therefore, the values of only these three parameters are shown in the Table I.

\subsection{Data collection and control cards}

Data collectors and control circuits in industrial control systems, in all branches of industrial applications, offer very effective general-purpose process automation solutions for users [3]. Data collector and control circuits can make data storage by converting to electrical signals the signals received via the sensors from the outside world. They can translate the data into different formats according to the purposes and can support a variety of data communication protocols. The control circuit that converts the signals from sensors to electrical signals in the prepared system is shown in Fig. 1 . RS-485 port and Modbus, supporting TCP communication protocol, were used.

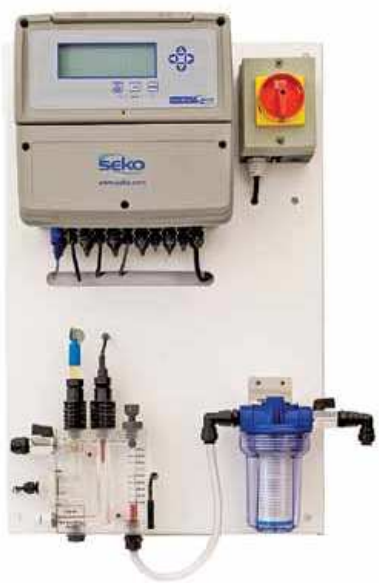

Fig. 1. Seko Control 800 data collection and control card.

\subsection{GSM transmission card and GSM PLC}

Today in the field of remote control of industrial applications, especially in smart home technology GSM transfer cards offer effective solutions to users. Especially with the expansion of the 3rd generation (3G) technology, GSM modems that allow internet access, independent of the position, have become attractive.
Input and output modules in the remote control and monitoring systems provide the exchange of information over the internet with field equipment. GSM transfer cards, unlike the GSM modems, contain input and output ports based on usage purpose. This allows GSM transfer cards to perform information reading and control operations of the field equipment. In the prepared system, GSM transfer card was used to collect the data read from the RS485 port on the control board into a virtual server in the Internet (Fig. 2).

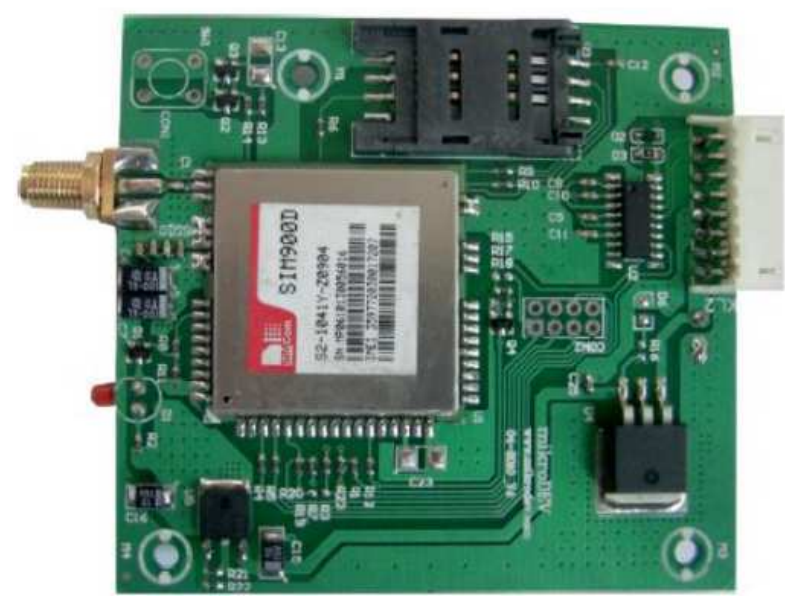

Fig. 2. GSM transmission card.

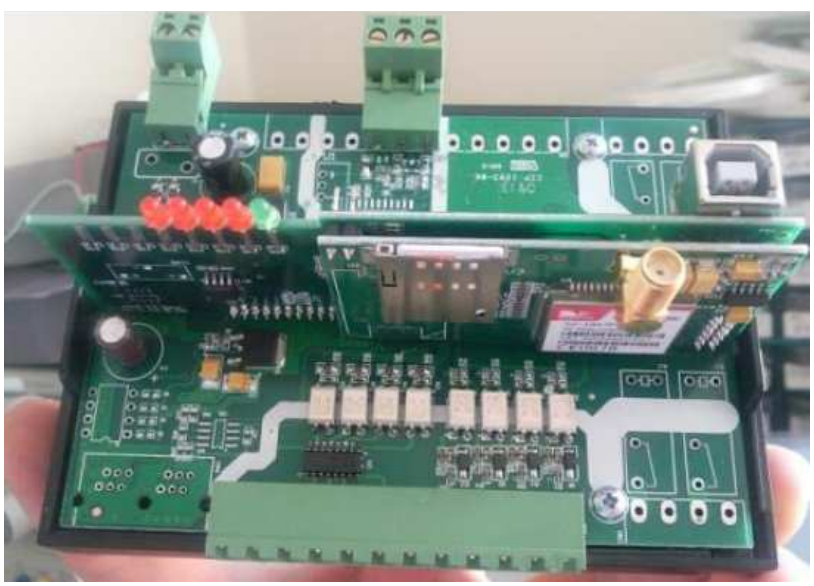

Fig. 3. GSM PLC.

The basic structure of a PLC consists of four main parts. These are the central processing unit CPU, input port, output port and programming. Although when the system was viewed from the outside it was not seen, a computer program that is required to program the PLC, panel program and control panel elements can be included in the basic structure of the PLCs [4]. PLC input and output ports are located as shown in Fig. 3. Additionally, GSM transmission card was added to PLC. GSM transfer card allows the PLC communication via GSM. An SMS sent to the SIM card inserted into the PLC is evaluated by the program loaded into the PLC. 
According to the received SMS, the type of procedure, which has to be performed by the PLC, is determined. According to the program that is loaded into the PLC, signal can be read from the designated input ports or SMS can be sent.

\subsection{Sensors}

Pt100 temperature sensor used in the system can operate with a precision of $0.5 \%$ in the basic range of $0-100^{\circ} \mathrm{C}$. In the extreme range from 200 to $800^{\circ} \mathrm{C}$, it can operate with a precision of $3 \%$.

$\mathrm{pH}$ is the parameter showing the acidity or alkalinity of a solution. $\mathrm{pH}$ is an abbreviation indicating the intensity of a solution of being acid- or base-like, and is an expression of the $\mathrm{H}^{+}$ion concentration in the solution. It is needed not only for monitoring the biological life of the surface water, but also should be verified and well known to provide chemical stability. The $\mathrm{pH}$ sensor used in this project is capable of measuring $\mathrm{pH}$ in the range of $0-14$. The measurement sensitivity value of the sensor is 0.01 . Sensor produces analog signal between 4 and $20 \mathrm{~mA}$, according to measured value. The sensor is connected via a BNC connector with other elements of the system.

Free chlorine is defined as chlorine which has not reacted with bacteria in the water and is capable of destroying the bacteria entering the water. Pool water must have between 1 and 3 ppm of free chlorine. Free chlorine concentration is very important to keep the optimum sterility of water. In the system, free chlorine sensor can measure concentration values between 0 and $5 \mathrm{ppm}$ by giving an analog signal between 4 and $20 \mathrm{~mA}$. Sensor is measuring with a sensitivity of 0.01 .

\subsection{Improved system structure}

The improved system, as shown in Fig. 4, contains sensors, data collection and control circuit, GSM transfer card, server computers, GSM PLC and dosing pumps.

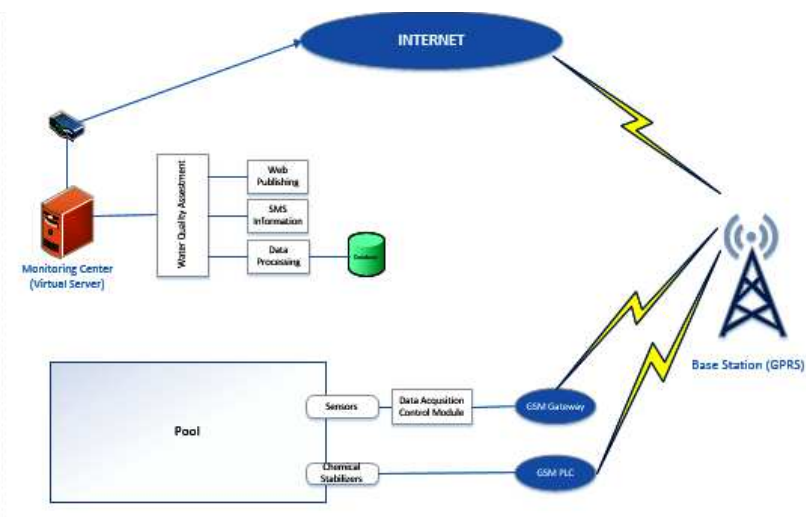

Fig. 4. Block diagram of water quality monitoring system of a swimming pool.

Measurement data from the GSM transfer card are stored using the software developed in $\mathrm{C} \#$ in a database located in the Water Quality Monitoring Center. The developed software stores measurement information in the database with a five second period. Optionally, the measurement delay can vary.
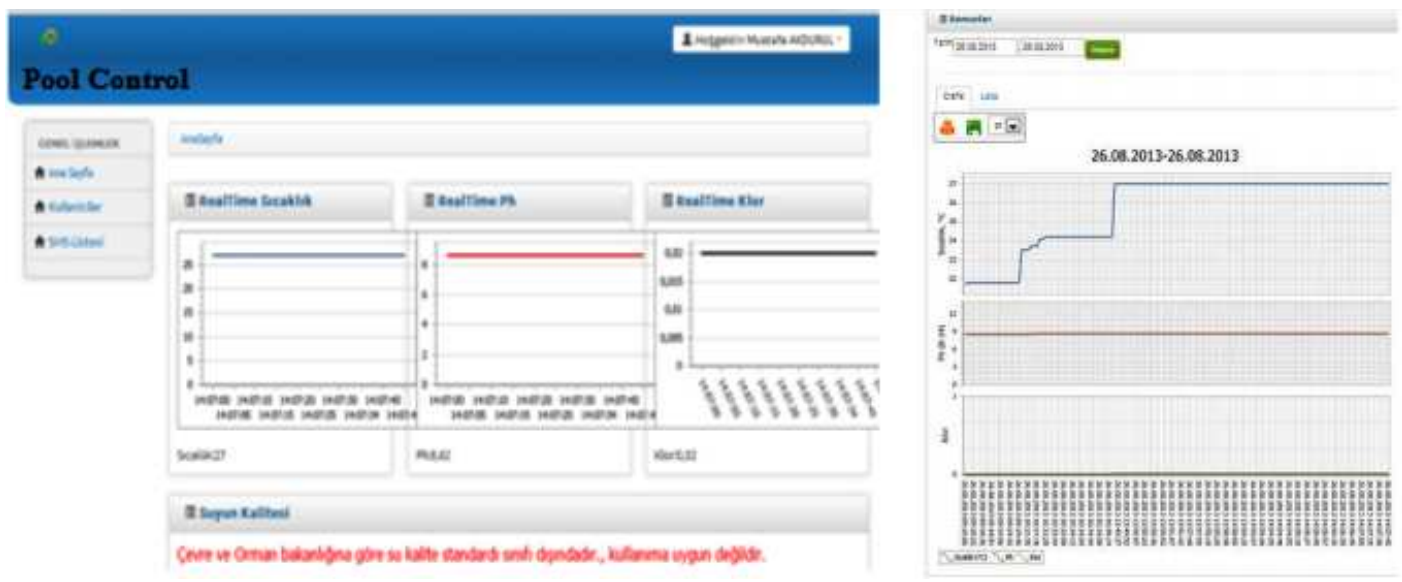

Fig. 5. Data monitoring pages.

It can be viewed as statistical data by using the improved web interface in Kullaniclar.Net architecture. In addition, users can receive SMSs with information about the quality of water by determining for themselves lower and upper alarm values or time period between messages, due to the improved web interface.
With expert system technique from artificial intelligence technology, by using data obtained from the sensors, the assessment of water quality can be made. According to the wording form of the information contained in the database, various inference mechanisms are available. The most commonly used information is 
named as wording style rule interpreter. In the construction of the interpreter, usually IF-THEN type of rules are utilized [5].

In the decision of water quality each degree is expressed by numbers. 1 exterior result, 2 dangerous limit, 3 optimal degree, 4 good degree, 5 represents excellent degree. The arithmetic average of the numerical value of each parameter is taken. According to the results web interface evaluates the water quality according to Table II.

\section{TABLE II}

Provision of quality value by quality class.

\begin{tabular}{c|c|c|c|c|c}
\hline \hline Quality class & I & II & III & IV & $\begin{array}{c}\text { Uncertainty } \\
\text { of measurement }\end{array}$ \\
\hline Quality value & 5 & 4 & 3 & 2 & 1
\end{tabular}

The SMS sending software, developed in C\#, stores are controls the fields containing user alarms and periodic notification time. In case of reaching any alarm or notification time period, it sends SMS to related users. Authorized users, having pool area status information, can perform control of the resistor or pump connected to the GSM PLC using the SMS commands. Thus, the chemical stabilization process of the pool can be done.

\section{Conclusions}

Water quality can be assessed using remote snapshots with the proposed improved system. The Decision
Support System software has been developed using the algorithm developed via expert system method. Water quality monitoring can be made from a single center with the support of provided software by adding new modules to the system in organizations such as the Ministry of Forestry and Water Affairs. Furthermore, the purpose of the system can be expanded by modifying the programming structure of the system controlled by GSM PLC.

\section{Acknowledgments}

This work was supported in part by Scientific Research Projects Unit of Süleyman Demirel University. (Project Number: 3450-YL2-13)

\section{References}

[1] Republic of Turkey Ministry of Health, Regulation on health principles that should be applied in the swimming pools, 2011, retrieved: 07.10.2014.

[2] Republic of Turkey Ministry of Environment and Forestry, Regulation on Water Pollution Control, 2004, retrieved: 21.10.2014.

[3] A.D. Gök, PLC Fundamentals and Applications, Okutman Publishing, Ankara 2008.

[4] Ç.I. Kabul, M.Sc. Thesis, Akdeniz University, Graduate School of Applied and Natural Sciences, Antalya, Turkey 2010.

[5] A. Tabur, Expert Systems and Artificial Intelligence, 2005, retrieved: 24.08.2013. 